\title{
PERANCANGAN KANTOR BISNIS RINTISAN MILENIAL DI KRAMAT PELA
}

\author{
Reynaldo ${ }^{1)}$, Fermanto Lianto ${ }^{2)}$ \\ 1)Program Studi S1 Arsitektur, Fakultas Teknik, Universitas Tarumanagara, welldonerocky@gmail.com \\ 2) Program Studi S1 Arsitektur, Fakultas Teknik, Universitas Tarumanagara, fermantol@ft.untar.ac.id
}

\begin{abstract}
Abstrak
Di era dimana generasi milenial semakin mendominasi dunia terutama di dalam dunia pekerjaan, batasan antara aktivitas bekerja dengan aktivitas-aktivitas lainnya semakin memudar. Namun karena karakteristik mereka yang cenderung fleksibel dalam segala hal, milenial juga cenderung lebih memilih untuk bekerja dimana saja selama ada koneksi internet dan stop kontak. Sebagai contoh, coffee shop atau kafe menjadi tempat yang popular untuk orang-orang milenial untuk bekerja di depan laptopnya. Sebagian dari mereka adalah merupakan startup entrepenur yang dimana mereka masih belum memiliki biaya untuk menyewa sebuah area kantor, sehingga dibutuhkan sebuah kantor bisnis rintisan yang sesuai dengan perilaku dan kesejamanan milenial. Oleh karena itu, terdapat 2 tujuan utama dari perancangan kantor bisnis rintisan ini; 1) menentukan dan mengkaji tipologi kantor startup yang secara efisien dan tepat untuk menyelaraskan perilaku generasi millennial dalam memulai dan menjalankan bisnis rintisan; 2) menerapkan hasil dari metode pattern language yang sesuai pada perancangan kantor bisnis rintisan ini. Agar perancangan kantor bisnis rintisan ini dapat dijalankan dengan baik dan sistematis, maka penyusun menggunakan metode pattern language menentukan zoning aktivitas manusia di area bangunan sehingga terbentuk alur-alur masuk dan keluar yang tepat dan jelas. Hasil akhir dari perancangan diharapkan dapat meningkatkan produktivitas pebisnis rintisan milenial yang di dukung oleh tipologi kantor bisnis rintisan yang tepat.
\end{abstract}

Kata kunci: Bisnis; Kantor; Milenial; Rintisan

\begin{abstract}
In this era where millennials increasingly dominating the world, especially in the world of works, the boundaries between working with other activities are increasingly fading too. But because of their characters whose tend to be flexible in everything, millennials also prefer to work anywhere as long as there is an internet connection and electricity sources. For example, a coffee shop or cafe is a popular place for millennials to work with their laptops. Some of them are startup entrepreneurs where mostly they don't have enough money to rent an office space, so that a startup business office is needed to suit with millennial behaviors and preferences. Therefore, there are 2 main objectives of the design of this startup business office; 1) to determine the startup office typology efficiently and precisely balancing the behavior of the millennial generation in starting and running a startup business; 2) to apply the results from the pattern language method that is appropriate for the design of this startup business office. In order for the design to be carried out properly and systematically, the compilers used the pattern language method to determine the zoning of human activities in the building area so that proper and clear in and out grooves are formed. The final results of the design are expected to increase the productivity of the millennial startup business supported by the typology of the appropriate startup business office.
\end{abstract}

Keywords: Business; Millennial; Office; Startup

\section{PENDAHULUAN}

Di era dimana generasi milenial semakin mendominasi dunia terutama di dalam dunia pekerjaan, batasan antara aktivitas bekerja dengan aktivitas-aktivitas lainnya semakin memudar. Namun karena karakteristik mereka yang cenderung fleksibel dalam segala hal, milenial juga cenderung lebih memilih untuk bekerja dimana saja selama ada koneksi internet 
dan stop kontak. Coffee shop atau kafe menjadi tempat yang popular untuk orang-orang bekerja di depan laptopnya. Sebagian dari mereka adalah merupakan startup entrepenur yang dimana mereka masih belum memiliki biaya untuk menyewa sebuah area kantor untuk mereka. Namun tidak dipungkiri bahwa orang-orang yang sudah bekerja di gedung-gedung kantor juga lebih memilih setidaknya sebuah kafe untuk bekerja (Andi Annisa Dwi Rahmawati, 2018). Namun, kebiasaan generasi milenial ini dapat menjadi ancaman bagi kantor-kantor yang bersifat tradisional, karena menurunnya minat generasi milenial bekerja dan melakukan aktivitas pekerjaan yang itu-itu saja di tempat/kantor yang bersifat seperti itu.

Startup di Indonesia telah berkontribusi besar untuk memperbanyak lapangan pekerjaan bagi kaum pekerja generasi muda. Banyak dari mereka memilih untuk berkerja di perusahaan startup. Namun terdapat satu permasalahan dasar pada Sumber Daya Manusia (SDM) dalam perusahaan startup ini. Secanggih apapun teknologi yang dipergunakan dalam suatu perusahaan dan modal perusahaan yang digunakan, namun karyawan di dalam perusahaanlah yang menjalankan tujuan perusahaan tersebut. Tanpa didukung oleh peran karyawan yang kompeten dalam perusahaan maka keberhasilan perusahaan tidak akan tercapai.

Oleh karena itu, dalam tugas perancangan arsitektur ini, penyusun mencoba untuk mengkaji kebutuhan tersebut dengan menyediakan fasilitas tempat kerja yang kondusif, tepat dan sesuai dengan tipe dan perilaku generasi milenial yang ada. Permasalahan yang dibahas dalam jurnal ini didasari oleh sebuah pertanyaan yang mendasar; bagaimana tipologi bangunan kantor bisnis startup yang dapat menyesuaikan tipe dan perilaku generasi milenial dalam bekerja dengan maksimal. Tujuan utama dari penelitian ini adalah untuk menentukan dan mengkaji tipologi kantor startup yang secara efisien dan tepat untuk menyelaraskan perilaku generasi milenial dalam memulai dan menjalankan bisnis startup

\section{KAJIAN LITERATUR}

\section{Perilaku Generasi Milenial dalam Bekerja}

Generasi milenial mendambakan kesetaraan dalam struktur perusahaan dan jalur komunikasinya. Keterbukaan tidak berarti apa-apa, jika ruang kantor pimpinan tidak mudah untuk diakses. Generasi milenial suka bekerja di lingkungan dengan pencahayaan alami, karena hal ini bagi mereka dipercaya mampu menimbulkan rasa keterbukaan dan kebersamaan, berkembangnya produktivitas. Generasi millennial lebih banyak menghabiskan waktu mereka bekerja untuk organisasi yang berkontribusi pada kesejahteraan bersama. Mereka melihat besarnya tantangan yang dihadapi dunia kelak, dan mengakui pentingnya mempertahankan tiga aspek kerja dasar akuntasi: aspek sosial, aspek lingkungan dan aspek finansial yang berkelanjutan. Mereka juga memberi lebih banyak penghasilan mereka untuk amal daripada generasi orang tua mereka (Argi Nuring, 2018).

Perusahaan startup cenderung menyediakan fasilitas yang sangat nyaman bagi para karyawannya mulai dari ruang kerja yang seperti ruang bermain, dengan adanya televisi, ruang game, warna ruangan yang cerah, terdapat ruang/tempat relaksasi adalah hal yang umum di ruang kerja startup ini hal ini agar karyawan dari perusahaan startup ini bisa mengeksplor ideide kreatif dari karyawan, merasa nyaman dengan tempat kerjanya sehingga termotivasi untuk berkerja, merasa bebas untuk mengembangkan kemampuan masing-masing individu di perusahaan startup ini, bagi karyawan lingkungan kerja yang nyaman ini akan memacu mereka berkerja lebih baik karena mereka tidak akan merasa jenuh dengan rutinitas yang monoton. (Argi Nuring, 2018). 


\section{Tipologi Layout Ruang Kerja dari Waktu ke Waktu}

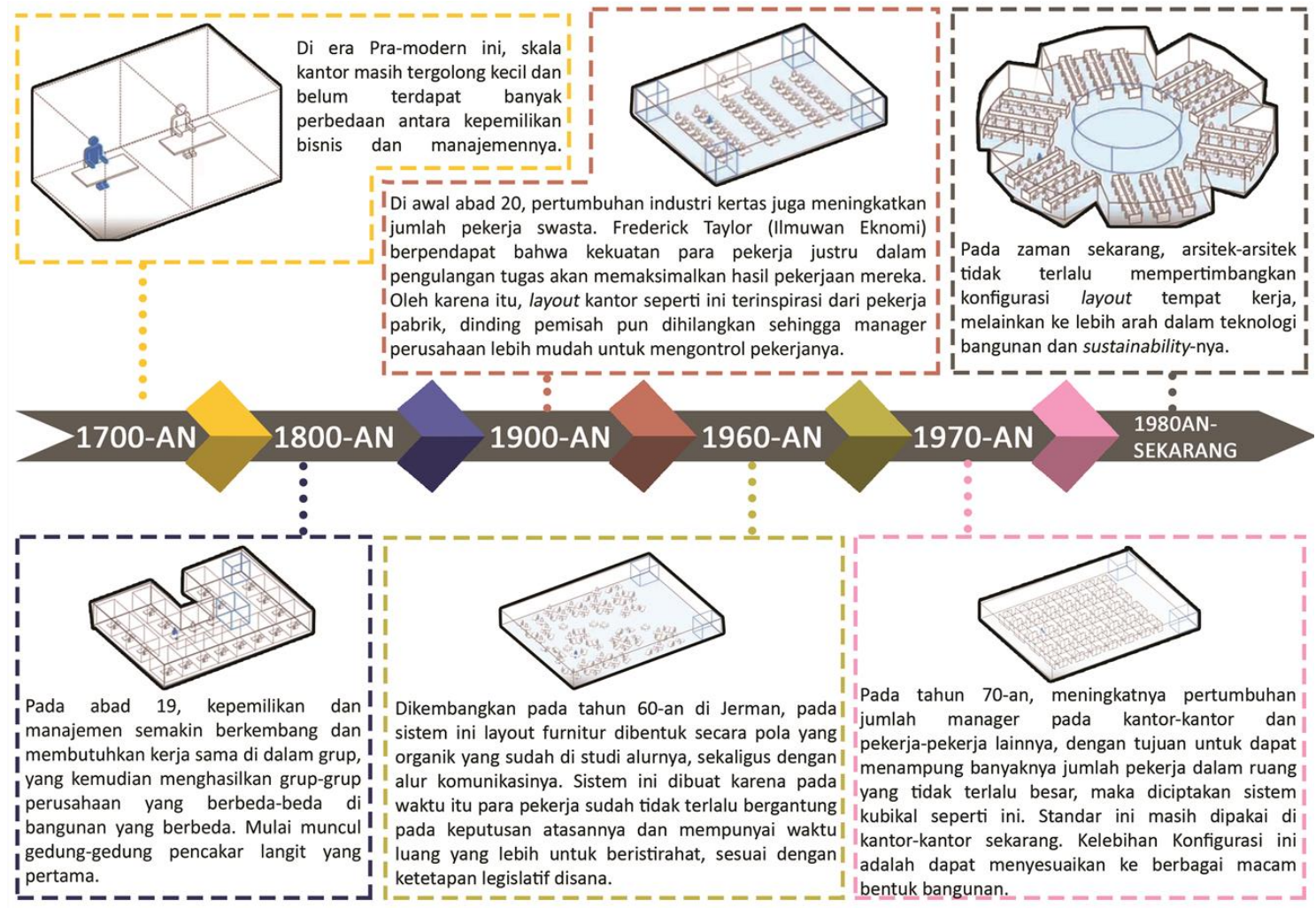

Gambar 1. Timeline Tipologi Layout Ruang Kerja dari Waktu ke Waktu

Sumber: Haotian Liu, 2012

\section{Struktur Organisasi}

Struktur organisasi dalam suatu pekerjaan merupakan hal yang selalu dimiliki oleh setiap perusahaan. Setiap perusahaan biasanya mempunyai sistem dimana hasil pekerjaan-pekerjaan karyawannya harus dilaporkan dan diserahkan terlebih dahulu ke managernya, dimana sang manager itu sendiri yang dapat memberikan persetujuan atau penolakan pada hasil-hasil ajuan laporan pekerjaan mereka sebelum diserahkan lagi kepada manager-mangarer yang tingkatannya lebih atas. Namun, berdasarkan thesis yang dilakukan oleh Haotian Liu dari Syracuse Univeristy School of Architecture tentang struktur system organisasi di perusahaan Facebook di New York, sistem mereka tidak seperti itu lagi, melainkan antar karyawan saling berkesinambungan dan masing-masing dapat memberikan feedbacks masing-masing dan lebih berkontribusi kepada projek yang dilakukannya (Haotian Liu, 2012).
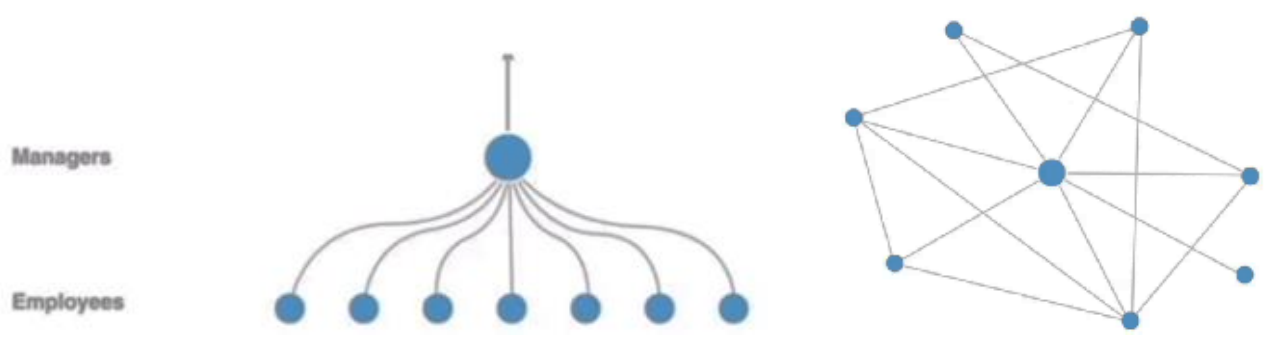

Gambar 2 dan 3. Struktur organisasi perusahan-perusahaan pada umumnya (kiri), Struktur organisasi di perusahaan Facebook, New York (kanan)

Sumber: Haotian Liu, 2012 
Tabel 1. Program Aktivitas Dasar di Kantor Startup

\begin{tabular}{|l|l|}
\hline Pengguna & Aktivitas \\
\hline Individu & $\begin{array}{l}\text { Menulis, menggambar, bertelepon, menjual, berfikir, membaca, } \\
\text { pengarsipan, komputasi, meneliti. }\end{array}$ \\
\hline Kolektif & Menjual, membuat persetujuan, pengarsipan, meneliti. \\
\hline Grup & $\begin{array}{l}\text { Mengajar, konseling, memonitor, mewawancara, rapat, proyek tim, } \\
\text { brainstorming, pelatihan, pengarahan, pameran karya. }\end{array}$ \\
\hline Bersosialiasi & Makan, minum, mengobrol, berolahraga, bermain pemainan. \\
\hline
\end{tabular}

Sumber: Ergin Dugyu, 2013

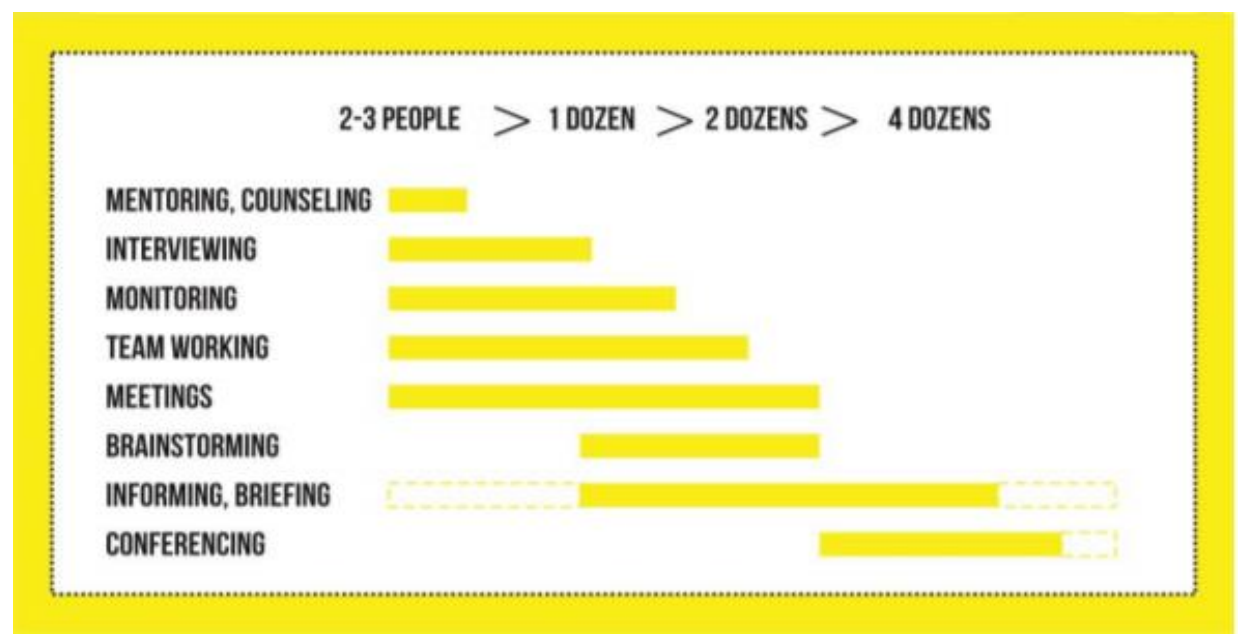

Gambar 4. Standar Jumlah Efektif Manusia dalam Melakukan Aktifitas yang Dilakukan Secara Bersamaan sehingga dapat Menghasilkan Produktifitas yang Maksimal Sumber: Ergin Dugyu, 2013

\section{METODE}

Metode yang digunakan dalam perancangan menggunakan metode pattern language. Metode pattern language digunakan untuk menentukan zoning aktivitas manusia di area bangunan sehingga terbentuk alur-alur masuk dan keluar yang tepat dan jelas (Alexander, 1977).

4. DISKUSI DAN HASIL Analisis Tapak

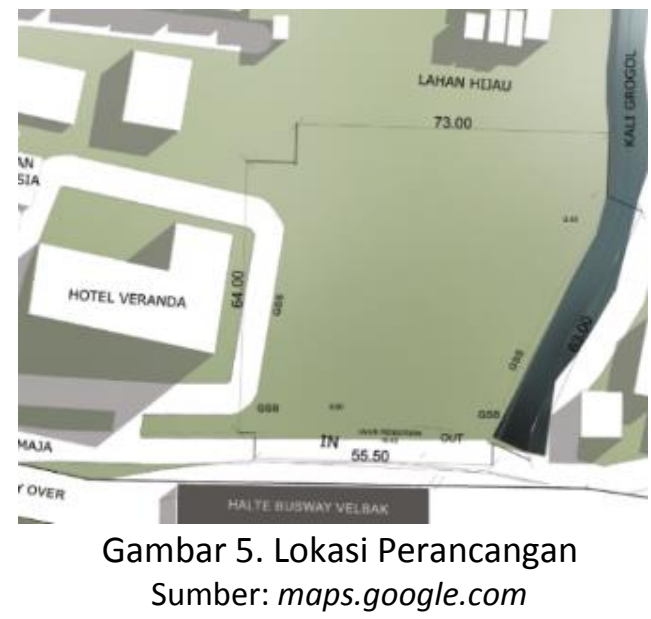


Tapak perancangan berlokasi di kelurahan Kramat Pela, Kebayoran Baru Jakarta Selatan. Tapak berbentuk trapesium dengan luas kurang lebih $3900 \mathrm{~m} 2$. Sisi utara tapak berbatasan dengan Jalan Kyai Maja, sisi Barat tapak berbatasan dengan Kali Grogol dan perumahan warga, sisi selatan tapak berbatasan dengan lapangan hijau dan sisi Timur tapak berbatasan dengan sisi barat Hotel Veranda. Eksisting tapak berupa rentetan bangunan ruko sewa 2 lantai tidak berpenghuni dengan lapangan hijau; di bagian belakang bangunan. Kontur tanah cenderung rata mengarah ke kali kecil; sisi barat tapak juga terdapat jalan lokal sekunder.

Tabel 2. Kriteria Lokasi Tapak Perancangan

\begin{tabular}{cl}
\hline Kriteria & \multicolumn{1}{c}{ Tapak } \\
\hline Letak & Dekat dengan jalan yang mengakses ke daerah Kebayoran Utara \\
\hline Eksisting & $\begin{array}{l}\text { Tanah lapang penghijauan dengan terdapat ruko 2 lantai sebagai } \\
\text { area pertokoan (fotokopi) yang mayoritas tidak terpakai/tutup } \\
\text { took. }\end{array}$ \\
\hline Denyut & Denyut ringan karena berada di depan jalan kolektor primer \\
\hline Transportasi/ & $\begin{array}{l}\text { Aksesibikitas ke tapak cukup mudah dilalui oleh berbagai } \\
\text { kendaraan umum maupun pribadi. Sirkulasi ke arah lokasi tapak } \\
\text { hanya memiliki 1 muka tapak yang menghadap jalan besar (Jl. } \\
\text { Kyai Maja) dengan lebar jalan sekitar 12 meter (3 lajur) sebagai } \\
\text { akses masuk dan keluar utama kendaraan. Pejalan kaki juga } \\
\\
\text { cukup mudah untuk akses ke tapak dengan kondisi eksisting } \\
\text { jalur pejalan kaki yang cukup baik }\end{array}$ \\
\hline Pencapaian & $\begin{array}{l}\text { Sangat mudah dicapai karena selain dicapai oleh berbagai } \\
\text { kendaraan umum, jalur kendaraan tidak macet dan terintegrasi } \\
\text { langsung oleh transjakarta flyover. }\end{array}$ \\
\hline Pemandangan & $\begin{array}{l}\text { Pemandangan semi-hijau dan tingkat kebisingan tidak sebising } \\
\text { area lain, keadaan sekitar banyak penghijauan dan kali kecil. }\end{array}$ \\
\hline
\end{tabular}

Pertimbangan dalam memilih lokasi tersebut untuk menyesuaikan kepentingan dan konsep desain kantor yang semi-privat-outdoor yang dibutuhkan yaitu lahan yang tidak terlalu dekat dengan jalur padat kendaraan umum namun tetap dapat mudah diakses oleh kendaraan umum, tidak ditengah kepadatan kota namun tetap berada dekat dengan area bisnis kota serta mendukung akses 24 jam yang tidak menganggu area perumahan ataupun area lainnya.

\section{Pola Bekerja Milenial}

\section{Kelebihan}

- Hemat biaya, akses cepat bisa dimana saja dan kapan saja.

- Tersedia fasilitas wifi dan stop kontak.

- Tidak memerlukan tempat bekerja yang "mengekang" milenial dalam melakukan pekerjaannya.

\section{Kekurangan}

- Tidak semua kafe bisa diakses selama 24 jam.

- Tidak menjamin kenyamanan milenial dalam bekerja karena dipengaruhi oleh seberapa cepat koneksi wifi, jumlah stop kontak, keramaian tempat,dsb.

- Kurang mendukung pengembangan kreativitas dalam bekerja, bergantung hanya pada sumber elektronik saja. 


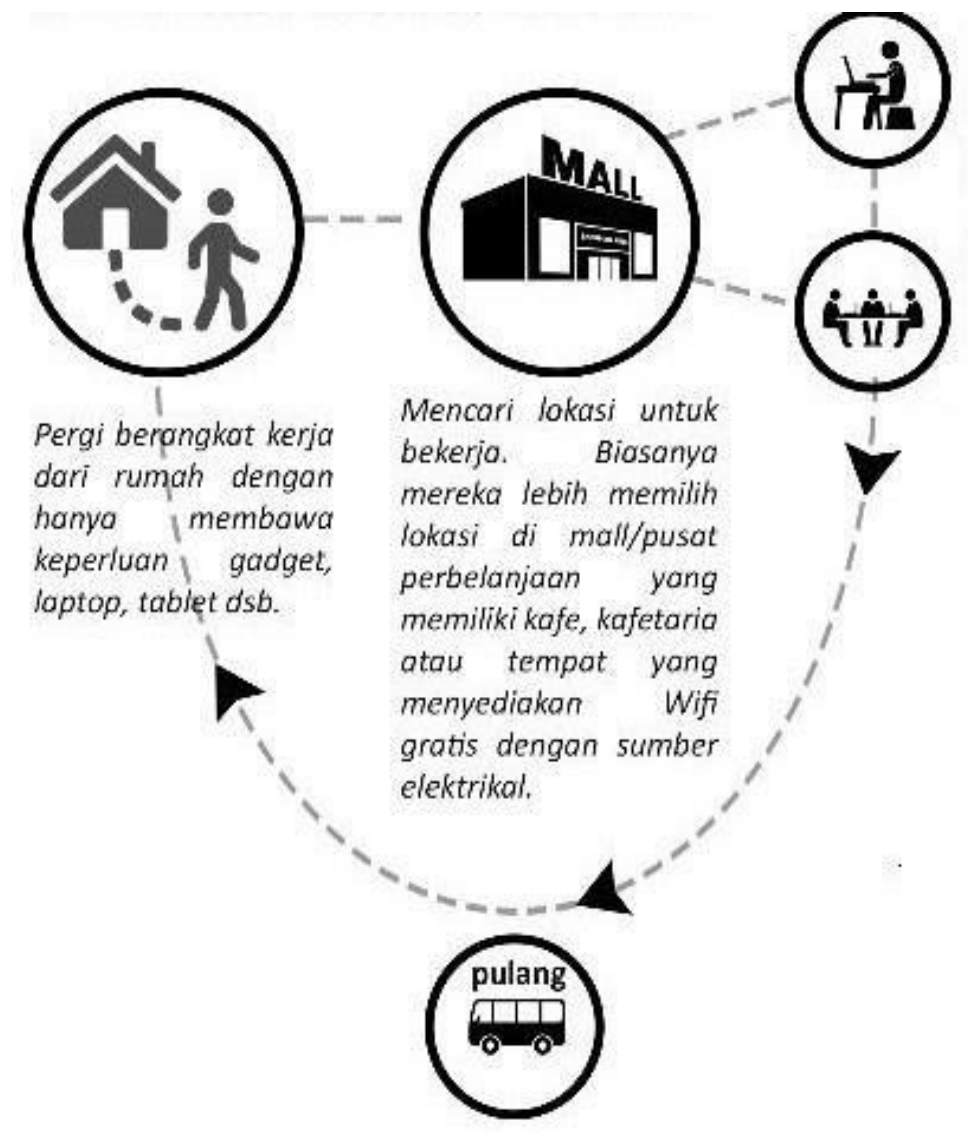

Gambar 6. Pola Bekerja Milenial

Sumber: Penulis, 2019

\section{Penerapan Metode Pattern Language pada Perancangan}

Oleh karena itu, startup entrepeneur milenial tetap membutuhkan sebuah wadah pengembangan dan fasilitas eksplorasi ide dan kreativitas dalam berbisnis startup yang dapat menyesuaikan pola perilaku mereka dalam bekerja dan digabungkan dengan hasil dari kajian teori, standar aktivitas dasar dan analisis tapak sehingga membentuk pola/pattern aktivitas sebagai berikut: 


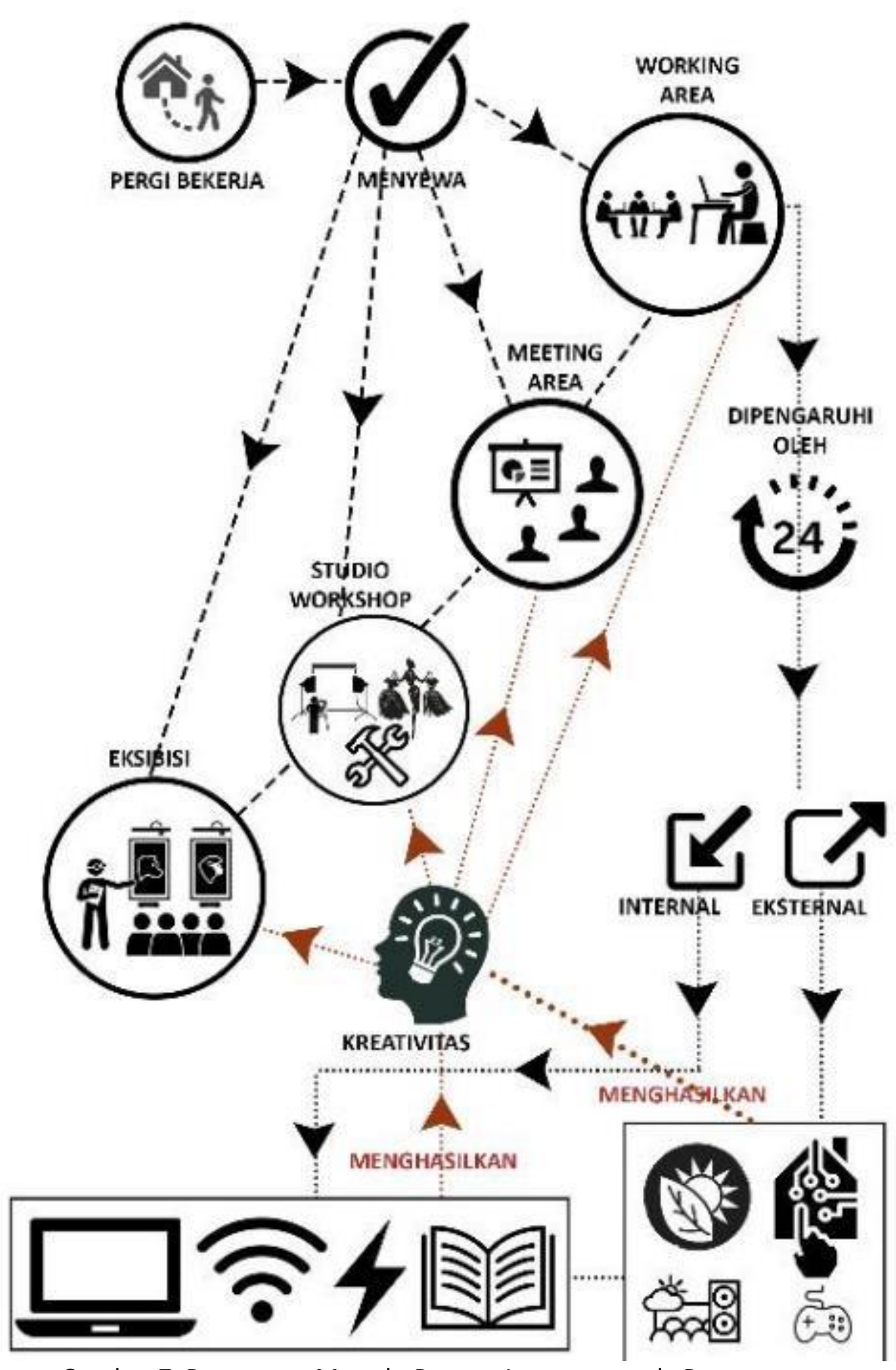

Gambar 7. Penerapan Metode Pattern Language pada Perancangan Sumber: Penulis, 2019

Pada lokasi perancangan, pebisnis usaha rintisan milenial dapat menyewa sesuai keinginan/kebutuhan dalam memaksimalkan eskplorasi idea kreatifnya lewat wadah yang tersedia seperti individual/group project working spaces, studio workshop, ekshibisi dalam 3 sektor industri kreatif seperti fesyen, fotografi/broadcasting dan produk DIY (referensi dari data statistik industri kreatif di kalangan milenial). Proses berkreatif tersebut tidak dipungkiri sangat dipengaruhi oleh aksesibilitas mudah 24 jam secara eksternal (komponen alam indoor outdoor, teknologi bangunan, entertainment area) dan internal (wifi, internet,dsb) pada fasilitas/desain bangunan yang memberikan dampak positif untuk kinerja mereka. 


\section{Skema Desain}

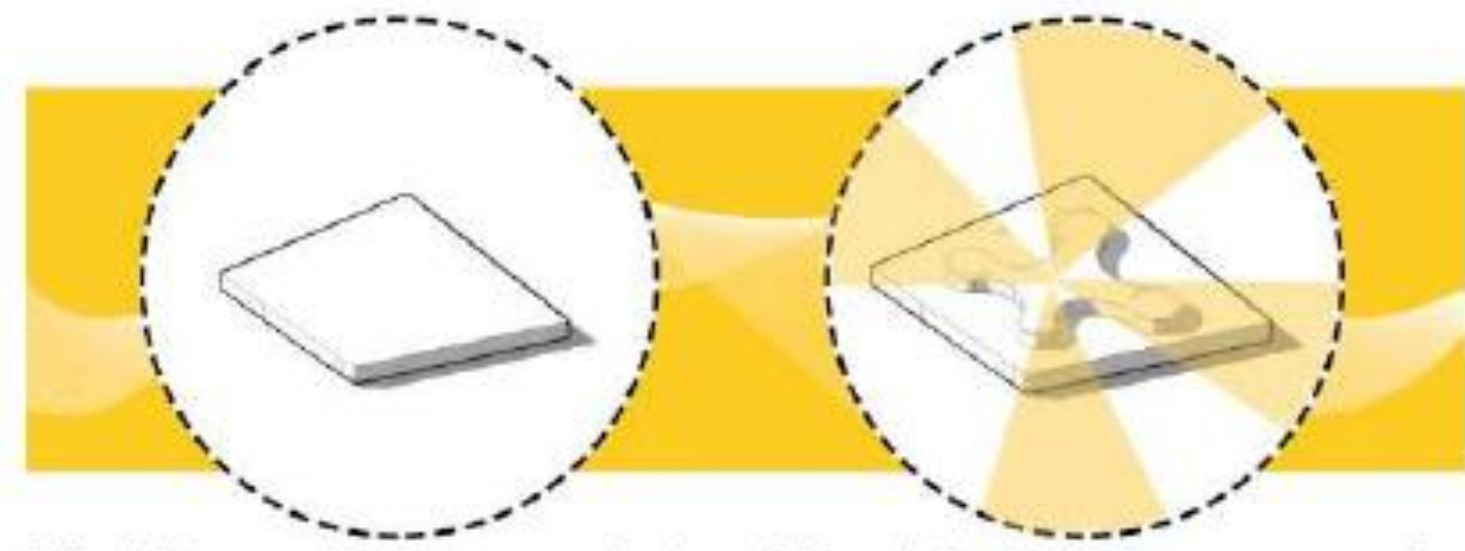

1. Kondisi site yang belum terprogram. Tapak beriokasi di Kramat Pela berupa lahan hijau seluas $3900 \mathrm{~m} 2$, bersebelahan dengan hotel Veranda dan kali Grogol.

2. Bentuk dasar bangunan yang menyesuaikan dengan hasil sintesa tapak dan potensi view ke luar dan ke dalam tapak, terbagi 4 penjuru potensi bisnis dengan 1 titik pusat di tengah.

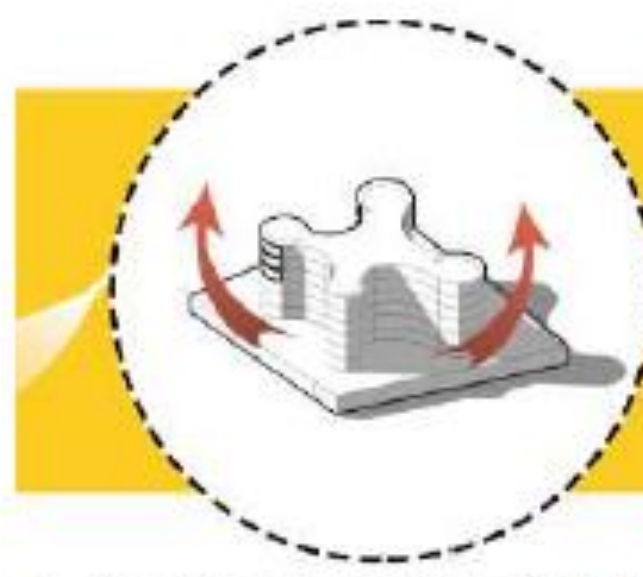

3. Keringgian bangunan dibuat hingga 5-6 lantai untuk menyesuaikan intensitas peraturan pembangunan. Total luas KLB adalah $\pm 6000 \mathrm{~m} 2$.

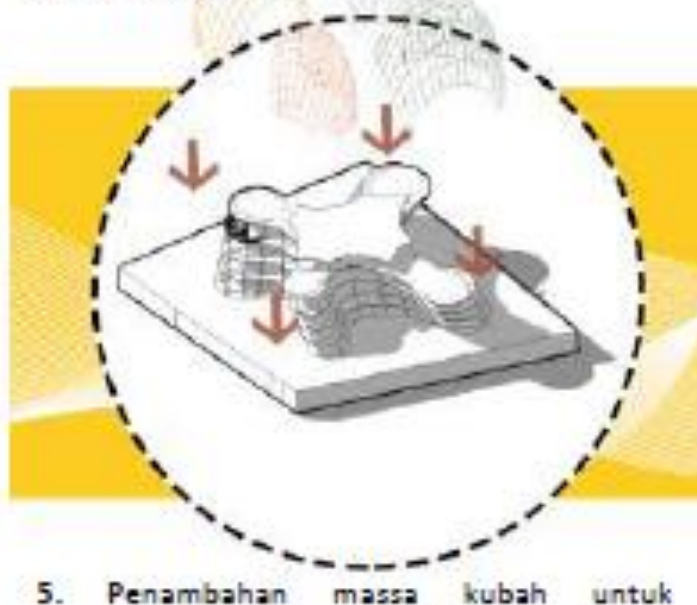
menciptakan sistem pendinginan khusus terhadap bangunan. Bermaterial Panel Perforated dan panel EFTE.
Gambar 8. Skema Desain

Sumber: Penulis, 2019
4. Massa bangunan per lantai dirotasikan sebesar kelipatan 3 derajat dari titik pusat searah jarum jam untuk menciptakan taman indoor untuk membantu mereduksi suhu udara bangunan di dalam dan diluar.

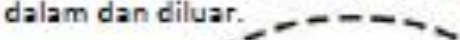

6. Massa akhir bangunan yang didominasi oleh seometri melengkung. 


\section{Pembahasan}

Penerapan metode pattern language dapat dilihat di gambar 9 dan 10. Di berbagai area pada kedua gambar di halaman 10, terdapat 3 macam warna (hijau, merah muda, kuning) yang menerjemahkan penerapan konsep pattern language yang dibuat ke dalam desain perancangan. Warna hijau menunjukan terdapatnya area hijau berupa void dan semi outdoor di setiap lantai yang berfungsi membantu mereduksi suhu panas di dalam bangunan secara alami dan dapat menciptakan pengalaman ruang dalam yang terkesan lebih nyaman, homey dan relaks. Hal ini tentunya dapat mendukung para pekerja/pebisnis startup milenial nyaman dalam bekerja dan mengeksplorasi ide dan kreativitas mereka. Pada gambar 9, area yang diwanai hijau pada bagian atas merupakan area rooftop outdoor working space yang berfungsi untuk area bekerja milenial dengan pengalaman ruang yang lebih berbeda, namun tetap bersifat semi privat, berupa taman kantor untuk menyesuaikan sifat milenial yang bersedia untuk bekerja tidak hanya di satu tempat dan dapat berpindah-pindah.

Warna merah muda pada gambar 9 menunujukan terdapat area teras semi outdoor. Teras ini berfungsi sebagai area peralihan udara panas dari luar ke dalam bangunan. Struktur cangkang sebagai pelindung terluar dari bangunan ini berfungsi untuk membantu mereduksi suhu panas di dalam bangunan dengan menggunakan material yang sangat ramah lingkungan seperti panel perforated dan lembaran EFTE (Ethylene Tetrafluoroethylene). Material ini merupakan bahan material generasi baru yang melebihi kaca. Penggunaan struktur membran ringan ini dapat meningkatkan desain, energi yang berkelanjutan dan kinerja bangunan ini. Pada area teras ini para pekerja milenial juga dapat melepaskan penat pekerjaan dan relaksasi dengan melihat pemandangan luar bangunan yang berupa area hijau pada taman di tapak perancangan dan area perkotaan yang dapat menciptakan suasana kondusif untuk memacu potensi munculnya ide dan kreativitas milenial dalam bekerja. Warna kuning menunjukan area sirkulasi pusat bangunan denga terdapat air terjun indoor yang menerus dari lantai teratas bangunan hingga lantai basement. Air tejun indoor ini berfungsi untuk membantu mendinginkan suhu ruangan secara alami terutama pada langtai basement dan dapat menciptakan pengalaman ruang yang rileks dan segar pada area lounge di setiap lantai bangunan. Konfigurasi furnitur dan layout ruangan di setiap lantai memiliki konsep yang bersifat open office dan organik, tidak lagi kubikal seperti tipologi kantor-kantor terdahulu. Dengan konfigurasi seperti ini, para pekerja/pebisnis startup milenial dapat bekerja dan mengeksplorasi ide dan kreativitas mereka dengan nyaman, bebas dan cocok dengan perilaku mereka. 


\section{Hasil Rancangan}

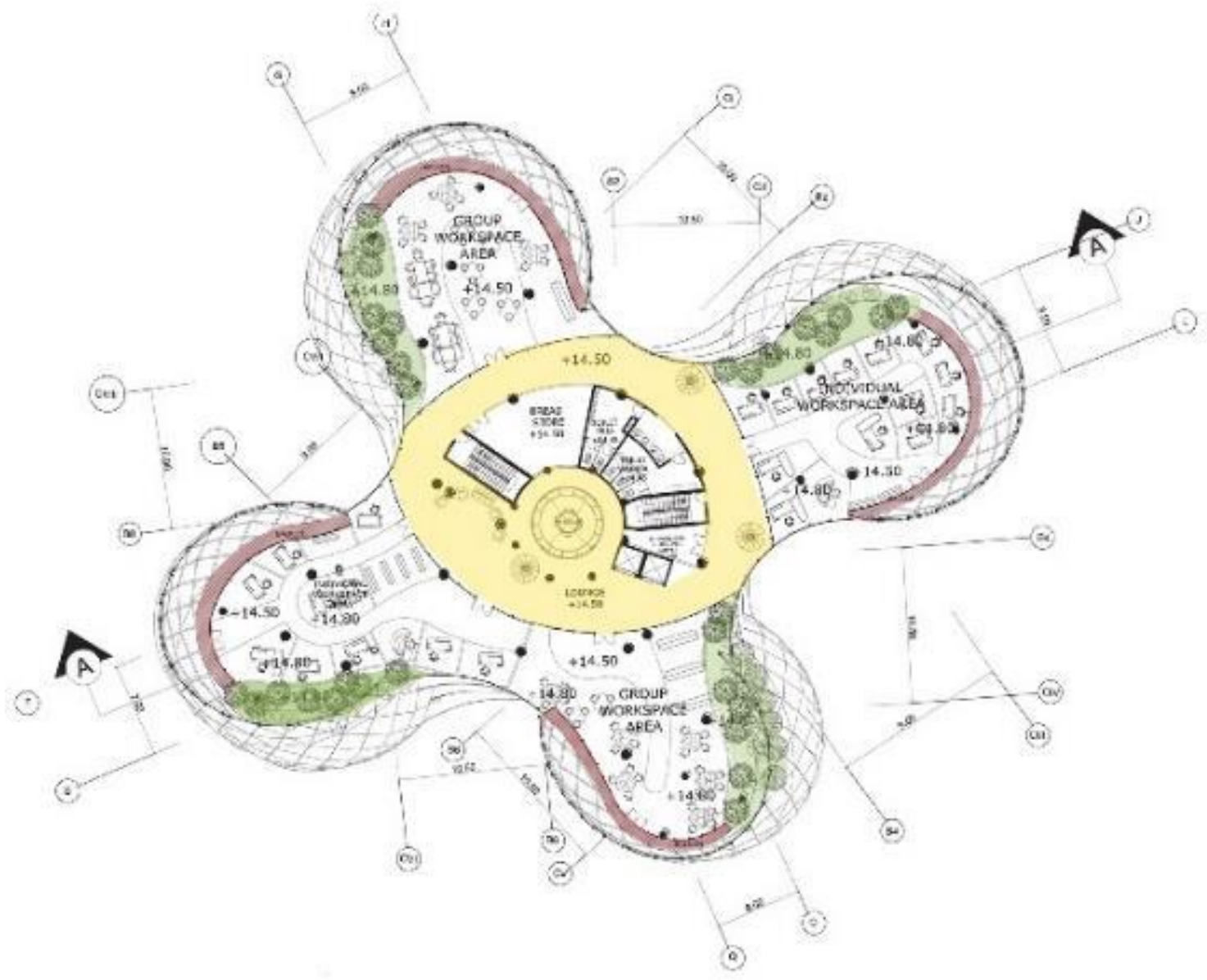

Gambar 9. Penerapan Metode Pattern Language dan Konsep Terhadap Denah, Konfigurasi Ruang dan Bentuk Sumber: Penulis, 2019

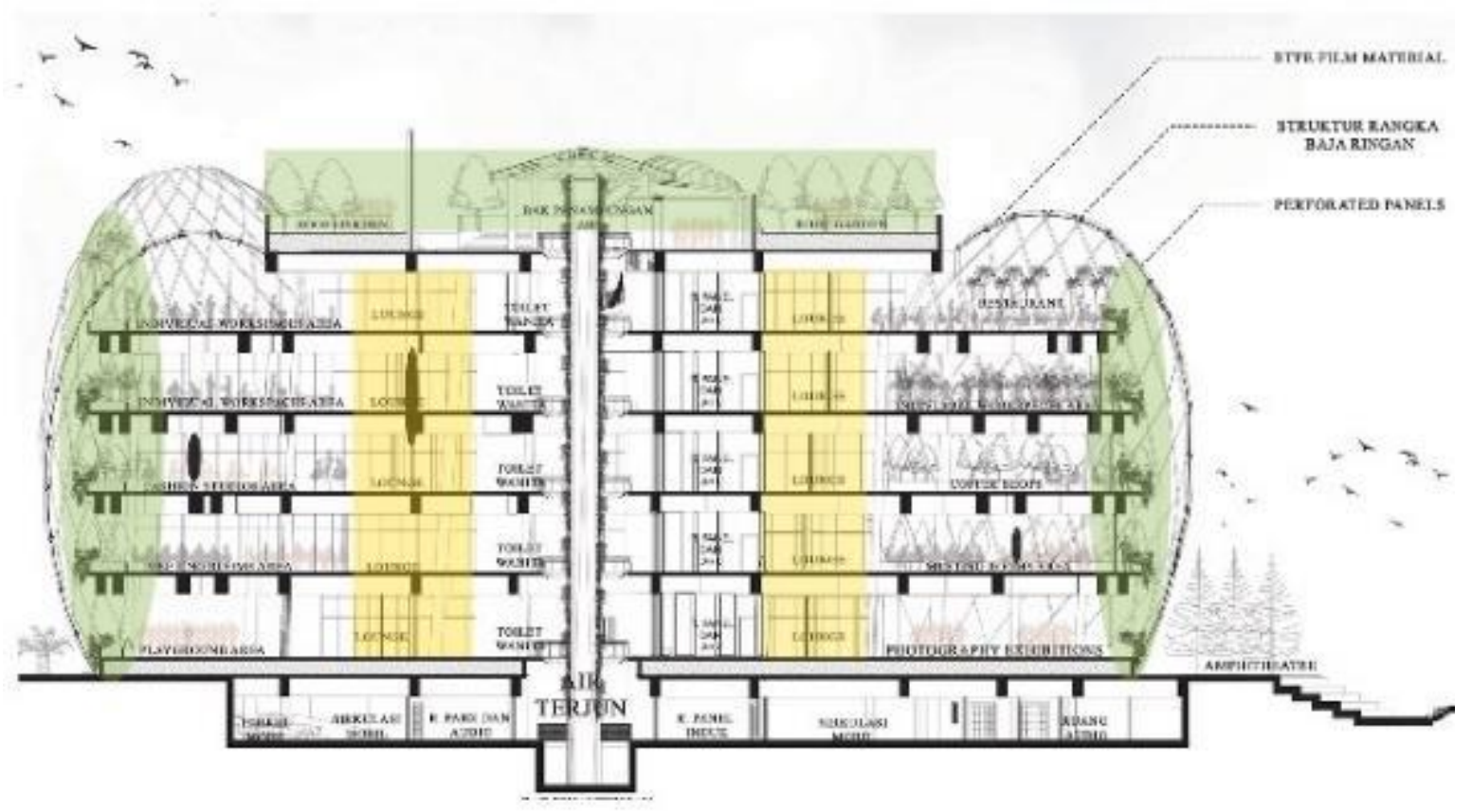

Gambar 10. Penerapan Metode Pattern Language dan Konsep Terhadap Potongan Bangunan Sumber: Penulis, 2019 


\section{KESIMPULAN DAN SARAN}

Berdasarkan dari hasil kajian perancangan di atas dapat diambil beberapa kesimpulan bahwa tipologi bangunan untuk kantor bisnis rintisan milenial yang dapat menyesuaikan dengan perilaku dan kesejamanan milenial dalam bekerja di lokasi Kramat Pela ini adalah dengan penggunaan konfigurasi ruang yang bersifat open plan office dan organic layout, disertai dengan penggunaan konsep green space yang maksimal baik secara indoor dan outdoor dan pattern language yang disesuaikan dengan hasil kajian teori dan analisis tapak.

\section{REFERENSI}

Alexander, C. (1977). A Pattern Language. New York: Oxford University Press

Dugyu, E. (2013). How to Create a Co-Working Space Handbook. Italy : hal 16

Jacob, M. (2016). 5 Tip Memperlakukan Generasi Millennial di Tempat Kerja. Diakses 3 Maret 2019, dari https://id.techinasia.com/tip-memperlakukan-generasi-millennial-di-tempatkerja

Liu, H. (2012). B.Arch Thesis Prep Fall. Syracuse Univeristy School of Architecture. Diakses 4 Maret 2019, dari https://surface.syr.edu/architecture_tpreps/196/

Nuring, A. (2018). 5 Cara Generasi Millennial Mengubah Budaya Kerja Dan Desain Kantor. Diakses 3 Maret 2019, dari https://www.arginuring.com/blog/2018/07/11/5-cara-generasimillennial-mengubah-budaya-kerja-dan-desain-kantor/

Rahmawati, A. A. D. (2018). Di Masa Depan Orang Akan Ngantor di Coffee Shop, Ini Alasannya. Diakses 4 Maret 2019, dari https://food.detik.com/info-kuliner/d-3795387/di-masa-depanorang-akan-ngantor-di-coffee-shop-ini-alasannya.

Ross, P. (2012). Typologies: Offices. Diakses 3 Maret 2019, dari https://www.architecturalreview.com/essays/typology/typology-offices/8633367.article 
